\title{
Polycyclic aromatic hydrocarbons (PAHs) degradation by laccase from a tropical white rot fungus Ganoderma lucidum
}

\author{
Hunsa Punnapayak ${ }^{1 \star}$, Sehanat Prasongsuk ${ }^{1}$, Kurt Messner ${ }^{3}$, Khanchai Danmek ${ }^{1,2}$ and \\ Pongtharin Lotrakul ${ }^{1}$
${ }^{1}$ Plant Biomass Utilization Research Unit, Department of Botany, Faculty of Science, Chulalongkorn University, Bangkok 10330, Thailand.
${ }^{2}$ Biotechnology Program, Faculty of Science, Chulalongkorn University, Bangkok 10330, Thailand. \\ ${ }^{3}$ Abteilung Mykologie, Institut für Biochemische Technologie and Mikrobiologie, Technische Universität Wien, A-1060 \\ Vienna, Austria.
}

Accepted 28 September, 2009

\begin{abstract}
Laccase enzyme was produced from an isolate of the white rot fungus, Ganoderma lucidum Chaaim-001 $B C U$. The enzyme was subsequently evaluated for its degradative ability towards sixteen types of polycyclic aromatic hydrocarbons (PAHs). The G. lucidum laccase degraded antracene completely with or without a redox mediator ( $2 \mathrm{mM}$ 1-hydroxybenzotriazole) and also degraded benzo[a]pyrene, fluorine, acenapthene, acenaphthylene and benzo[a]anthracene up to 100.0, 98.6, 95.4, 90.1 and $85.3 \%$, respectively, when the mediator was present. In the absence of the mediator, the ability to degrade these compounds dropped to $71.71,62.9,80.49,85.85$ and $9.14 \%$ respectively. Compared to the laccase enzyme from Trametes vesicolor, G. Iucidum laccase appeared to retain more of its capability to degrade these PAHs when the mediator was absent.
\end{abstract}

Key words: Laccase, Ganoderma lucidum, polycyclic aromatic hydrocarbons.

\section{INTRODUCTION}

Lignin is the second most abundant renewable organic polymer on earth and is a major component of wood. Its degradation is an important and integral part of ecosystem. Moreover, because of the importance of lingocellulose based compounds and especially wood in the production of paper, feeds, chemicals and fuels there is much interest in lignin degradation (Boominathan and Reddy, 1992). The white rot basidiomycetous fungi are believed to be the most effective lignin-degrading microbes with the production of lignin-modifying enzymes (LMEs) including lignin peroxidase (LiP, E.C. 1.11.1.14), manganese peroxidase (MnP, E.C. 1.11.1.13) and laccase (Lac, E.C.1.10.3.2) (Pointing, 2001). Laccase is multi-copper containing oxidase (O'Malley et al., 1993)

\footnotetext{
*Corresponding author. E-mail: phunsa@chula.ac.th.
}

which catalyzed the monoelectric oxidation of a range of inorganic and aromatic substances with relatively low redox potentials with the concomitant reduction of $\mathrm{O}_{2}$ to water (Baldrian, 2006), including degradation of lignin and related compounds (Xu, 1996). The redox potential of laccase is rather low and less than those of non-phenolic substrates, which would be expected to limit their role in lignin degradation. However, in the presence of an appropriate effective redox mediator, or laccase-mediator system, laccases can oxidize the non-phenolic lignin structure (Bourbannais and Paice, 1996; Bourbannais et al., 1997).

Due to their abilities to degrade lignin and other phenolic compounds, laccase has been widely applied to different biotechnological processes, such as biopulping with a patented Lignozyme ${ }^{\circledR}$ process and the degradation of synthetic dyes as part of the waste treatment process in the textile industry (Howard et al., 2003). Moreover, the 
combined action of intracellular cytochrome P450 and extracellular laccase and peroxidase enzyme reactions enable white rot fungi to degrade a variety of toxic organopollutants, such as polychorinated phenols, polychlorinated dibenzo-p-dioxins and polycyclic aromatic hydrocarbon (PAHs) and other xenobiotics (Boominathan and Reddy, 1992).

PAHs are recognized as a group of chemicals that are formed during the incomplete burning of coal, oil, gas, or other organic substances, contain several fused benzene rings and are biotoxic compounds with potentially carcinogenic and mutagenic properties (Cerniglia, 1997). Indeed, PAHs are currently regarded as ones of EPA-priority pollutants.

Members of white rot basidiomycetous fungi have been reported as one group of organisms which extensively mineralize the recalcitrant PAHs due to their abilities to produce ligninolytic enzymes (Pointing, 2001). Certain white rot fungi have been well recognized for these capabilities including Pluerotus sp., Phanerochaete chrysosporium, P. laevis, Trametes versicolor (Pointing, 2001) and Agrocybe sp. (Chupungars et al., 2009). Recently an isolate of Ganoderma lucidum was identified as a dominant laccase producer (Murugesan et al., 2007). However, the ability of tropical white rot fungi, including $G$. lucidum, for PAHs degradation has yet to be described.

In this research, we investigated the ability of the laccase enzyme in the crude extracellular extract from a tropical isolate of white rot fungus, G. Iucidum Chaaim$001 \mathrm{BCU}$, to degrade PAHs with or without the presence of 1-hydroxybenzotriazole (HOBT) as a redox mediator.

\section{MATERIALS AND METHODS}

The G. lucidum isolate Chaaim-001 BCU (isolated from tree stump in Pattani, Thailand) was maintained on potato dextrose agar (PDA) slants and deposited in the Fungi Section of Herbarium of Plant Biomass Utilization Research Unit, Department of Botany, Faculty of Science, Chulalongkorn University. The culture was subsequently transferred to yeast malt agar (YMA, Difco) plates and incubated at $30^{\circ} \mathrm{C}$ for growth. The fungus was tested for thermotolerance by incubating at $25,30,35,40$ and $45^{\circ} \mathrm{C}$ and monitoring the growth by measuring the colony diameter. The crude extracellular extract containing laccase was prepared from the culture filtrates of the fungus grown in a semi-solid state cultivation on eucalyptus paper pulp (Punnapayak et al., 2005). The medium was filtered, assayed for laccase activity and the liquid filtrate was further concentrated by membrane filtration (10,000 Da MW cut off, Millipore). The assay for laccase activities was performed in triplicate using 2,6-dimethoxy phenol (2,6-DMP, Sigma) as the substrate (Bourbonnais and Paice, 1990). For the PAHs degradation test, sixteen of the EPA-priority pollutants including acenaphthene (ACE), acenaphthylene (ACY), anthracene (ANT), benzo[a]anthracene $(\mathrm{BaA})$, dibenzo[ah] anthracene (BahA), benzo [a]pyrene $(\mathrm{BaP})$, benzo[b]fluoranthene $(\mathrm{BbF})$, benzo[ghi]perylene (BghiPER), benzo[k]fluoranthene (BkF), chrysene (CHR), fluoranthene (FLA), fluorene (FLU), indole[123-cd]pyrene (IcdPYR), naphthalene (NAP), phenanthrene (PHE) and pyrene (PYR) were evaluated as substrates. Each PAH was dissolved to the final con- centration of $16 \mathrm{ppm}$ in $0.3 \%(\mathrm{w} / \mathrm{w})$ tween 80 . The reaction mixture $(600 \mu \mathrm{l})$ consisted of $1.52 \mathrm{U} / \mathrm{ml}$ laccase, $50 \mathrm{mM}$ sodium acetate buffer $(\mathrm{pH} 5.0), \mathrm{PAH}$ solution and water with or without the presence of HOBT as the redox mediator. The reaction mixture was incubated in darkness for three days at $30^{\circ} \mathrm{C}$ with agitation $(120$ rpm) and then stopped by the addition of $600 \mu \mathrm{l}$ acetonitrile. The degradation profile was detected by HPLC (Hewlett Packard series 1100) as previously described (Srebotnik and Hemmel, 2000).

\section{RESULTS AND DISCUSSION}

The G. lucidum species complex is one of the most broadly distributed white rot fungi, thriving in both temperate and tropical areas. It is of interest to investigate whether this isolate (Chaaim-001 BCU) of the fungus, obtained from a tropical country like Thailand, is thermotolerant. G. lucidum Chaaim-001 BCU grew well at $30^{\circ} \mathrm{C}$, it grew poorly to not at all at temperatures above $30^{\circ} \mathrm{C}$ and thus appeared to not be thermotolerant. When cultivated on eucalyptus pulp, G. Iucidum Chaaim-001 BCU yielded a laccase activity up to $0.507 \mathrm{U} / \mathrm{ml}$. This crude enzyme preparation was further concentrated by membrane filtration (10,000 Da MW cut off) to 7.5 fold increased activity and was then used for the subsequent PAHs degradation test. Sixteen types of PAH were used as substrates to evaluate the degradation activity by this crude laccase preparation. A crude laccase from Trametes versicolor, a known PAH-degrading basidiomycetes fungus, was included for comparison as a reference.

When assayed for degradation, NAP could not be detected from the HPLC peaks, presumably because NAP was vaporized under the HPLC condition used in this study and thus was excluded from further analysis. Under the above fungal growth and extract assay conditions a higher level of degradation was observed when HOBT was present and appeared essential for degradation to any extent for seven of the $15 \mathrm{PAHs}$ (BahA, $\mathrm{BbF}$, BghiPER, BkF, CHR, FLA and PYR) for the extract from $T$. versicolor and were degradable for that from $G$. lucidum Cha-aim-001 BCU (4/7; BahA, BkF, CHR and PYR) (Table 1). In the presence of HOBT, all 15 of the tested PAHs were degraded to some extent by the $T$. versicolor laccase, although only 11 of these were at levels above $40 \%$. Only 13 and 6 PAHs were degraded at levels greater than 80 and $40 \%$, respectively, by the $G$. lucidum Chaaim-001 BCU laccase. Complete degradation of FLU, ANT, BaA and BaP was observed under these conditions with the $T$. versicolor laccase, whereas only ANT and BaP were completely degraded by the $G$. lucidum Chaaim-001 BCU laccase. The lowest degradation level detected with the $T$. versicolor laccase was $1.59 \%$ for FLA whereas G. lucidum Chaaim-001 BCU laccase did not degrade BbF, IcdPYR and FLA. In the absence of HOBT, $T$. versicolor laccase dramatically lost its capability to degrade PAHs, especially BkF, BahA, 
Table 1. Percent degradation of PAHs by laccases from G. lucidum Chaaim-001 BCU and $T$. versicolor.

\begin{tabular}{|l|c|c|c|c|}
\hline \multirow{3}{*}{ PAHs } & \multicolumn{4}{|c|}{ Degradation (\%) } \\
\cline { 2 - 5 } & \multicolumn{2}{|c|}{ Laccase from T. versicolor } & \multicolumn{2}{|c|}{ Laccase from G. Iucidum $^{*}$} \\
\cline { 2 - 5 } & With mediator & Without mediator & With mediator & Without mediator \\
\hline ACE & 92.00 & 48.35 & 95.36 & 80.49 \\
ACY & 73.64 & 40.18 & 90.09 & 85.85 \\
ANT & 100.00 & 79.55 & 100.00 & 99.41 \\
BaA & 100.00 & 1.30 & 85.30 & 9.14 \\
BahA & 93.68 & 0.00 & 36.53 & 0.00 \\
BaP & 100.00 & 31.10 & 100.00 & 71.71 \\
BbF & 38.69 & 0.00 & 0.00 & 0.00 \\
BghiPER & 93.16 & 0.00 & 20.33 & 0.00 \\
BkF & 79.65 & 0.00 & 21.71 & 0.00 \\
CHR & 37.34 & 0.00 & 7.93 & 0.00 \\
FLA & 1.59 & 0.00 & 0.00 & 0.00 \\
FLU & 100.00 & 15.71 & 98.63 & 62.86 \\
IcdPYR & 85.84 & 0.00 & 0.00 & 0.00 \\
PHE & 25.85 & 2.14 & 11.53 & 7.45 \\
PYR & 89.64 & 0.00 & 30.71 & 0.00 \\
\hline
\end{tabular}

${ }^{*}$ Compared to the control reaction (without enzyme added).

BghiPER, IcdPYR and PYR, whilst only one PAH (ANT) was degraded more than $50 \%$. In the absence of HOBT, expecting the seven common PAHs that neither the $T$. versicolor laccase nor the $G$. lucidum laccase could degrade (BahA, BbF, BghiPER, CHR, FLA and IcdPYR), the laccase from $G$. lucidum Chaaim-001 BCU appeared to retain a greater $\mathrm{PAH}$-degrading capability than that of $T$. versicolor. Almost the same level of degradation was observed when ANT, ACY and ACE were exposed to $G$. lucidum Chaaim-001 BCU laccase with and without HOBT, whilst more than $50 \%$ degradation of FLU and $\mathrm{BaP}$ was observed. In most reports of PAHs degradation by microbial laccases, a redox mediator was found to be important for accelerating such degradation. For example, addition of the synthetic redox mediator ABTS was reported to increase the oxidation rate of phenanthrene by the $T$. versicolor laccase by about $40 \%$ (Han et al., 2004), whilst the degradation of PAHs by laccase from the white rot fungus, Rigidoporous lignosus, was reported to be insignificant without the addition of a mediator (Cambria et al., 2008). However, we found that the laccase from both $T$. versicolor and $G$. lucidum could degrade some PAHs, although less efficiently, without the addition of $\mathrm{HOBT}$ redox mediator.

\section{Conclusion}

The laccase produced from G. lucidum Chaaim-001 BCU isolate was able to degrade some of $12 / 15$ tested types of PAH and could degrade antracene completely with or without a redox mediator. The enzyme could also degrade benzo[a]pyrene, fluorine, acenapthene, acenaphthylene and benzo[a]anthracene at high (> 80\%) and medium (> 60\%) degradation levels when the redox mediator was present or not, respectively. It is of interest that G. lucidum Chaaim-001 BCU laccase was still able to degrade such compounds without a redox mediator given its expected lower redox potential and this paradox awaits further investigation to solve.

\section{ACKNOWLEDGMENTS}

The authors wish to thank Oesterreichischer Austauschdienst (Austria), the Royal Golden Jubilee (RGJ) Ph.D. grant 2. B. CU /47/ F. 1 contract number PHD/0168/2547 and the Ministry of Education, Thailand for financial supports. Valuable suggestions from Prof. Dr. E. Srebotnik are highly appreciated. Technical assistance from $P$. Wulz, M. Weisgram and T. Kuncinger are acknowledged.

\section{REFERENCES}

Boominathan K, Reddy CA (1992). Fungal degradation of lignin: biotechnological applications, Arora DK, Elander RP, Mukerji KG (ed)., In handbook of applied mycology, Vol. 4. Marcel Dekker Inc., New York, pp. 763-822.

Pointing SB (2001). Feasibility of bioremediation by white-rot fungi. Appl. Microbiol. Biotechnol. 57: 20-33.

O'Malley DM, Whetten R, Bao W, Chen CL, Sederoff R (1993). The role 
of laccase in lignification. Plant J. 4: 751-757.

Baldrian P (2006). Fungal laccases-occurrence and properties. FEMS. Microbiol. Rev. 30: 215242.

Xu F (1996). Oxidation of phenols, anilines, and benzenethiols by fungal laccases: correlation between activity and redox potentials as well as halide inhibition. Biochemistry, 35: 7607-7614.

Bourbannais R, Paice MG (1996). Enzymatic delignification o9f Kraft pulp using laccase and a mediator. TAPPI. J. 79: 199-204.

Bourbonnais R, Paice MG (1990). Oxidation of nonphenolic substratesan expanded role for laccase in lignin degradation. FEBS. Lett. 267: 99-102.

Bourbonnais R, Paice MG, Freiermuth B, Brodie E, Borneman S (1997). Reactivities of various mediators and laccases with Kraft pulp and lignin model compounds. Appl. Environ. Microbiol. 63: 4627-4623.

Howard RL, Abotsi E, Jansen van Rensburg EL, Howard S (2003). Lignocellulose biotechnology: issues of bioconversion and enzyme production. Afr. J. Biotechnol. 2: 602-619.

Cerniglia CE (1997). Fungal metabolism of polycyclic aromatic hydrocarbons: past, present and future applications in bioremediation. J. Ind. Microbiol. Biotechnol. 19: 324-333.

Chupungars K, Rerngsamran, and Thaniyavarn S (2009). Polycyclic aromatic hydrocarbons degradation by Agrocybe sp. CU-43 and its fluorene transformation. Int. Biodeterior. Biodegrad. 63: 93-99.
Murugesan K, Nam IH, Kim YM, Chang YS (2007). Decolorization of reactive dyes by a thermostable laccase produced by Ganoderma lucidum in solid state culture. Enzyme Microbiol. Technol. 40: 16621672.

Srebotnik E, Hemmel KE (2000). Degradation of non-phenolic lignin by the laccase- /1-hydroxybenzotriazole system. J. Biotechnol. 81: 179188.

Punnapayak H, Kuhirun M, Watanabe T (2005). Liquid-state prebleaching of paper pulp with white rot fungi. J. Natl. Res. Council, Thailand. 37: 25-35.

Han MJ, Choi HT, Song HG (2004). Degradation of phenanthrene by Trametes versicolor and its laccase. J. Microbiol. 42: 94-98.

Cambria MT, Minniti Z, Librando V, Crambria A (2008). Degradation of polycyclic aromatic hydrocarbons by Rigidoporus lignosus and its laccase in the presence of redox mediators. Appl. Microbiol. Biotechnol. 149: 1-8. 